\title{
Herbal Viagra and Nitric Oxide: How Hard is the Evidence?
}

\author{
John P. Cooke ${ }^{1}$ \\ 1. Stanford Cardiovascular Institute, Stanford University School of Medicine \\ $\square$ Corresponding author: John P. Cooke, jpcooke@tmhs.org \\ Disclosures can be found in Additional Information at the end of the article
}

\section{Abstract}

A central role of endothelium- and neuronal-derived nitric oxide (NO) in erectile function is strongly supported by pre-clinical studies and human data. This endogenous vasodilator increases penile blood flow and tumescence. An impairment of NO synthesis and/or bioactivity plays a major role in erectile dysfunction in many patients. Indeed, effective pharmacotherapy for impotence augments the action of endogenous NO; Viagra ${ }^{\circledR}$ was the first of these drugs to market. By increasing the stability of cyclic guanosine monophosphate (GMP) (the 'second messenger' of NO) phosphodiesterase-5 inhibitors, such as Viagra ${ }^{\circledR}$, enhance NO-induced penile blood flow. A number of dietary supplements are purported to be herbal equivalents of Viagra ${ }^{\circledR}$, by enhancing NO synthesis and/or bioavailability. This review examines the evidence for these claims.

Categories: Internal Medicine

Keywords: vascular disease, cyclic gmp, endothelium, impotence, soluble guanylyl cyclase, vasodilation, erectile dysfunction

\section{Introduction And Background}

\section{Abbreviations:}

Asymmetric dimethylarginine- ADMA

Cyclic guanosine monophosphate- cGMP

Dimethylarginine dimethylaminohydrolase- DDAH

Endothelial nitric oxide synthase- eNOS

Nitric oxide- NO

Published 08/15/2010

๑) Copyright 2010

Cooke. This is an open access article distributed under the terms of the Creative Commons Attribution License CC-BY 3.0., which permits unrestricted use, distribution, and reproduction in any medium, provided the original author and source are credited.
Nitric oxide synthase- NOS

Soluble guanylyl cyclase- sGC

Coronary artery disease- CAD

Peripheral arterial disease- PAD 


\section{Review}

\section{Etiology of erectile dysfunction}

Erectile dysfunction is the inability to maintain a penile erection that is sufficient for sexual intercourse. There are multiple etiologies, both psychological and physical. With respect to the latter, erectile dysfunction may be the manifestation of neuropathy (such as that associated with the autonomic neuropathy of diabetes mellitus, or with surgical or radiological treatments of pelvic pathology); with structural alterations in the penis (as with Peyronie's disease); hormonal disturbances (as with low testosterone levels); adverse effects of certain medications (such as hormonal therapy for prostate cancer) or vascular disease (as with atherosclerotic obstruction of the internal iliac arteries, or with vascular dysfunction). Of these, vascular dysfunction may be the most common cause of erectile dysfunction. Vascular dysfunction is commonly observed in individuals with hypertension, diabetes mellitus, insulin resistance, hypercholesterolemia, aging or tobacco use, and with atherosclerosis. Notably, impotence may be the first indication that an individual is at serious risk of cardiovascular disease, and this symptom may be a harbinger of stroke or heart attack. Thus, because of its implications for the physical and mental well-being of the individual, men that are having difficulty with sexual function should seek early medical attention, and be evaluated for serious underlying diseases often associated with this condition. Self-treatment with over-the-counter remedies, without the evaluation of a physician, places the individual at serious risk.

\section{Pharmacotherapy for erectile dysfunction}

There are a number of effective drugs to treat impotence. Individuals with low testosterone levels benefit from testosterone replacement therapy. Other treatments include the selfinjection of vasodilators, such as alprostadil. Injection of this vasodilator prostanoid into the base or shaft of the penis increases penile blood flow to induce tumescence. Other vasodilators for injection include papaverine and phentolamine. An alternative approach is the intraurethral application of alprostadil.

However, these approaches have been overtaken by the phosphodiesterase- 5 inhibitors (PDE- 5 inhibitors), which are very effective as oral therapy in the treatment of impotence [1]. These drugs include sildenafil, tadalafil (Cialis ${ }^{\circledR}$ ), and vardenafil (Levitra ${ }^{\circledR}$ ). The PDE-5 inhibitors increase penile blood flow by inhibiting the degradation of cyclic guanosine monophosphate (cGMP) by its phosphodiesterase (Figure 1). This molecule relaxes vascular smooth muscle. It does so by activating protein kinases that phosphorylate proteins that reduce cytosolic calcium levels, or that dephosphorylate the myosin light chains of vascular smooth muscle [2].

As can be seen from the figure, cGMP is the 'second messenger' of nitric oxide. Nitric oxide and other nitrovasodilators activate soluble guanylate cyclase, which produces cGMP from GTP. The PDE-5 inhibitors prevent the degradation of cGMP, thereby increasing and prolonging its effect to relax vascular smooth muscle, so as to increase blood flow. The PDE-5 inhibitors were initially developed to treat hypertension. Their effect to reduce systemic vascular resistance (and thereby reduce blood pressure) was modest, but a rather positive effect on erectile dysfunction was observed. This serendipitous observation was made possible by the fact that NO is a major mediator of penile blood flow. 


\section{Cureus}

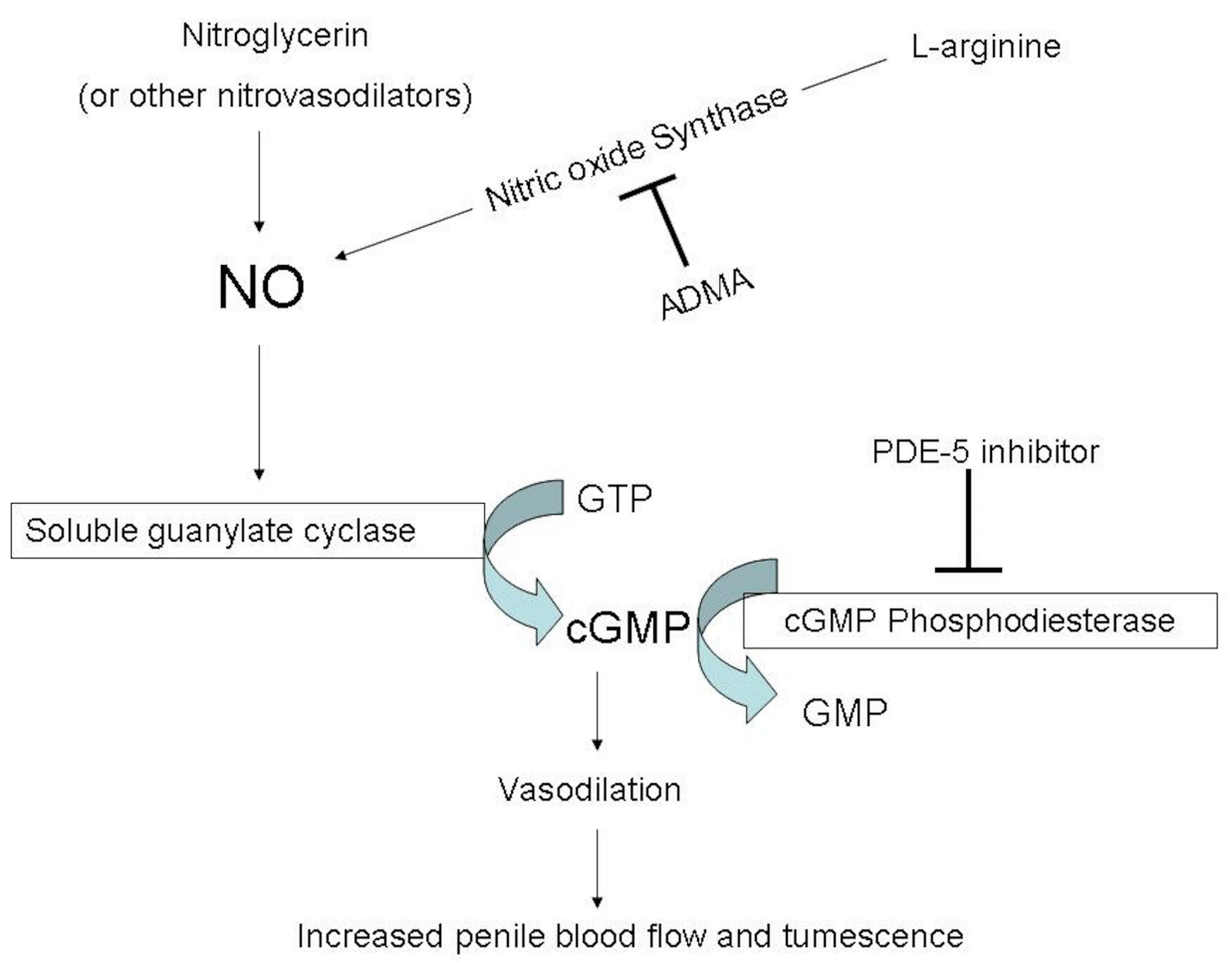

FIGURE 1: NOS inhibitor, ADMA (asymmetric dimethylarginine).

\section{The central role of $\mathrm{NO}$ in penile tumescence}

In 1998, the Nobel Prize was awarded to three US pharmacologists (Drs Fend Murad, Robert Furchgott and Louis Ignarro) for their discovery and characterization of a unique signaling molecule, the gas nitric oxide (NO). First discovered to be a vasodilator produced by the endothelium lining the blood vessels, it is now known that NO can be made by neurons, macrophage, and other cells, and has diverse functions in the body [3]. In the vasculature, NO released by the endothelium induces vasodilation and increases blood flow. In the penile circulation, this function of the endothelium is supplemented by release of NO from nitrergic nerve terminals within the penis [4].

NO synthesized by the endothelial isoform of NO synthase (NOS) in the endothelium, and by the neuronal isoform (nNOS) in the nitrergic nerves. The NOS enzymes metabolize L-arginine to NO and L-citrulline (Figure 1). Both isoforms are present in the penis, nNOS in the nerve terminals of penile autonomic nerves (pelvic plexus, cavernous and dorsal nerves) and eNOS in the endothelium of the cavernosal cisternae and arteries [5-7]. Penile tumescence is achieved by a collaboration of these two NOS signaling pathways [8]. In response to sexual stimulation, the nitrergic nerves are activated, releasing NO to induce vasodilation. Penile blood flow increases, creating a tractive force (shear stress) on the endothelium. Endothelial shear stress is known to induce vasodilation, secondary to phosphorylation and activation of eNOS $[9,10]$. Endothelium-derived NO then amplifies and sustains the increase in penile blood flow [11].

Any alteration in either of these NO signaling pathways can attenuate penile blood flow and cause erectile dysfunction. For example, traumatic or metabolic injury to the cavernous nerve reduces nNOS activation, and causes erectile dysfunction. In the case of cavernous nerve injury model, sildenafil is capable of enhancing the action of eNOS to preserve erectile function [12]. 
However, the major cause of NOS impairment in the western world is dysfunction of endothelial NOS. The ability of the endothelium to respond to shear stress or other stimuli, and to induce relaxation of the underlying vascular smooth muscle, is impaired in older individuals, and those with diabetes, hypertension, hypercholesterolemia, or tobacco exposure [13, 14]. An impairment of endothelial NOS not only reduces the ability of a blood vessel to relax, but also broadly disrupts vascular homeostasis. In addition to relaxing vascular smooth muscle, NO is a potent inhibitor of platelet adhesion and aggregation $[15,16]$. In addition, NO suppresses vascular inflammation by reducing the expression of leukocyte adhesion molecules and inflammatory cytokines [17-20]. Because of these powerful effects of NO on vascular homeostasis, enhancement of NO synthesis (as with L-arginine administration or overexpression of eNOS protein) has been shown in animal models to reduce the progression of atherosclerosis and myointimal hyperplasia [21-23]. The importance of NO in vascular homeostasis is supported by a large number of studies revealing that an impairment of endothelial vasodilator function is an independent risk factor for cardiovascular morbidity and mortality [24-26].

Similarly, there is strong evidence from pre-clinical studies and clinical investigation, that derangements of the NO synthase pathway can cause erectile dysfunction, and that therapy to augment NO signaling is therapeutic. In the penile tissue of animals with experimentally induced hyperglycemia, and in the corpora cavernosa from patients with diabetes mellitus, there is an impairment in NO synthesis [27]. This has been attributed to impaired eNOS protein expression and activity and increased oxidative stress [28, 29].

Diabetes mellitus is associated with mitochondrial dysfunction and oxidative stress [30] that can accelerate the degradation of NO [31]. Furthermore, diabetes mellitus favors the production of advanced glycosylation endproducts (AGEs) which can also disrupt eNOS activation, as with formation of $\mathrm{N}$-acetylglucosamine (OGICNAc) adducts with serine phosphorylation sites on eNOS. [29, 32]. With aging, alterations in the phosphorylation and activation of eNOS is observed in experimental animals [33], an effect that can be reversed by sildenafil [34]. Hypercholesterolemia enhances the inhibitory interaction of caveolin-1 with eNOS; an effect that can be may be reversed by diet and exercise [35].

\section{L-arginine: rationale for its use in vascular diseases}

In a number of cardiovascular disorders associated with erectile dysfunction (eg. diabetes, hypercholesterolemia, hypertension), the ability of the endothelium to induce vasorelaxation is impaired [14]. Our group was the first to provide evidence that administration of L-arginine could restore endothelial vasodilator function and enhance NO synthesis in animal models of disease, and in humans with endothelial vasodilator dysfunction [21, 36, 37]. Initially our findings faced significant skepticism [38]. The major criticism was that in vitro, the Km of NOS for L-arginine is in the range of 2-3 uM [39]. Because L-arginine exists in the plasma at concentrations of about $100 \mathrm{uM}$, the concentration of L-arginine should not be rate-limiting. But despite the calculations of enzymologists, and in apparent contradiction of MichaelisMenton kinetics, our observations were confirmed by a number of other groups [40-45]. In a rather broad range of cardiovascular disorders, it appears that the endothelial vasodilator dysfunction observed in these conditions can be reversed, at least in the short-term, by oral or intravenous administration of L-arginine supplementation. Furthermore, the improvements in endothelial vasodilator dysfunction have been associated with increased NO synthesis, and improvements in symptoms in patients with coronary artery disease, congestive heart failure, and peripheral artery disease [46-50]. The discrepancy between the in vitro calculations and the in vivo observations has been termed the arginine paradox [51]. There have been several explanations proffered for the arginine paradox, but one of the most compelling is the existence of an endogenous NOS inhibitor. 


\section{The arginine paradox and ADMA}

Sometime after our observation that arginine restored NO signaling, Patrick Valiance and colleagues demonstrated the existence of endogenous antagonists of the NOS pathway [52]. The methylarginines are methylated analogues of L-arginine. These include monomethylarginine (MMA), asymmetric dimethylarginine (ADMA) and symmetric dimethylarginine (SDMA). The methylarginines are metabolites of the hydrolysis of proteins containing methylated arginine residues [53]. Both ADMA and MMA are capable of competing with L-arginine for binding to the NOS enzyme, whereas SDMA does not. Since ADMA and MMA are competitive inhibitors of NOS, their antagonism of NOS can be reversed by increasing the concentration of L-arginine [14].

The plasma concentration of ADMA and MMA are increased in renal failure. About $20 \%$ of the clearance of these compounds is due to renal excretion. The remaining $80 \%$ of clearance is largely due the action of the cytoplasmic enzyme dimethylarginine dimethylaminohydrolase (DDAH); [54] which is expressed ubiquitously as two isoforms [55]. This enzyme is exquisitely sensitive to oxidative stress because it expresses a sulfhydryl group in its catalytic site [56]. We have shown that the enzyme activity is impaired with a number of disorders associated with cardiovascular disease including hypercholesterolemia, diabetes mellitus, and hyperhomocysteinemia [57-59]. In humans, ADMA is elevated in all of the conditions associated with cardiovascular disease [14]. In addition, in humans ADMA is a predictor of the severity and progression of atherosclerosis and myointimal hyperplasia, and is an independent predictor of cardiovascular morbidity and overall mortality [60-63]. Of relevance to this review ADMA is increased in patients with erectile dysfunction, and levels correlate with the severity of erectile dysfunction [64]. Plasma ADMA levels are higher in ED patients with CAD, than in those without CAD [65]. ADMA remains a strong and independent predictor for CAD in patients with ED, even after adjusting for the usual CV risk factors [65]. Because the PDE-5 inhibitors do not appear to restore normal plasma levels of ADMA [66], it is theoretically possible that the efficacy of these agents could be enhanced by the administration of L-arginine. On the strength of the pre-clinical studies and clinical investigations, there is a strong scientific foundation for clinical trials to assess L-arginine supplementation as a method to improve NO signaling in cardiovascular disease, and its utility in promoting sexual function.

\section{L-arginine: an herbal Viagra?}

In a model of atherosclerosis in Sprague-Dawley rats, Park and colleagues found that by comparison to control animals, cavernosal ADMA was increased in association with a decline in DDAH activity, and an impairment in NO synthesis [67]. Cavernosal ADMA was negatively correlated with the intra-cavernosal pressure [67]. These findings may explain the observations of others, supporting the use of supplemental L-arginine for erectile function. In one of these, oral administration of L-arginine for $8 \mathrm{wk}$ to aged rats resulted in an increase in penile tissue levels of L-arginine, an increase in NOS activity and a complete reversal of age-related erectile dysfunction [68]. Gur and co-workers found that L-arginine could relax strips of isolated human corpus metabolized to NO by NOS, had no effect. The effect of L-arginine was due to its conversion to NO, as L-NAME (a NOS inhibitor) and ODQ (an antagonist of cGMP synthesis) blocked the effect of L-arginine, whereas sildenafil potentiated the arginine induced relaxation. These observations demonstrated that supplemental L-arginine (in addition to the endogenous levels of L-arginine in the tissue) could induce relaxation by increasing NO synthesis.

Several small clinical trials are supportive of L-arginine supplementation for erectile function. In one small clinical study of 20 impotent men using a placebo controlled, crossover design, Larginine administered orally ( $2.8 \mathrm{~g} / \mathrm{d}$ for $2 \mathrm{wk})$ subjectively restored erectile function as well as vaginal penetration ability in 6 of 15 patients completing the study [69]. This beneficial effect was not reported during the placebo phase [70]. In a subsequent randomized clinical trial, L- 
arginine $5 \mathrm{~g} /$ day was administered for 6 weeks [71]. Nine of 29 (31\%) patients taking L-arginine and two of 17 controls reported a significant subjective improvement in sexual function using a validated questionnaire. All nine patients treated with L-arginine who improved were noted to have low urinary NOx at the initiation of the study. The level of urinary NOx in this subgroup had doubled by the end of the study, suggesting that patients with low levels of NOS activity may be particularly benefited by L-arginine supplementation [71]. Not all studies have been positive. In a small randomized clinical trial with cross-over design, 32 patients with impotence were administered L-arginine ( $1.5 \mathrm{~g} /$ day) or placebo. There was no subjective improvement in erectile function [72]. The major difference between this trial and the others was the smaller dose of L-arginine in the negative trial, which may have been ineffective at increasing plasma L-arginine levels [73].

Several studies have examined the use of L-arginine in combination with other nutritional agents. Lebret and co-workers [74] studied the combination of yohimbine $(6 \mathrm{mg})$ and Larginine (6g) daily in a randomized clinical trial with cross-over design $(n=45$; treatment periods of two weeks). Erectile function was modestly but significantly improved by comparison to placebo for the primary endpoint of change in the Erectile Function Domain of the International Index of Erectile Function (IIEF). In a randomized placebo controlled study, Gentile and colleagues assessed in 40 diabetic patients a dietary supplement product containing a combination of propionyl-L-carnitine, L-arginine and nicotinic acid [75]. Erectile function was estimated with the International Index of Erectile Function (IIEF5) questionnaire. The group receiving the dietary supplement product (group A, $\mathrm{n}=10$ ) was compared to those receiving vardenafil $20 \mathrm{mg}$ twice weekly (Group B, $\mathrm{n}=10$ ); or the combination of vardenafil with the dietary supplement(group C, $n=10$ ), or double placebo (Group D n=10). At the end of treatment, the group receiving placebo showed no change in the IIEF5. By contrast, the group receiving vardenafil alone manifested an increment of 4 points on the IIEF5. The group receiving the dietary supplement had 50\% of the improvement of the vardenafil group. There was a tendency of the group receiving both vardenafil and the supplement to have a slightly better outcome.

Another recent study assessed a dietary supplement product that contained L-arginine aspartate and pycnogenol [76]. Pycnogenol is derived from pine bark extract and contains oligomeric proanthocyanidins that have anti-oxidant effects. In a randomly allocated, doubleblind, placebo-controlled, crossover design, 50 patients with mild to moderate erectile dysfunction (ED) were administered for 1 month a placebo or the combination of L-arginine aspartate and pycnogenol. Patients reported sexual function from diaries. One month of treatment was associated with subjective improvement, and increased frequency of intercourse.

\section{How hard is the evidence?}

What is apparent from the discussion above is that though the pre-clinical foundation is strong, the clinical evidence is weak for the utility of L-arginine as a therapeutic adjunct in the treatment of erectile dysfunction. The clinical trials have been conducted in small groups of patients, and for the most part have used subjective indices of erectile function without objective assessments (eg. penile plethysmography). Proper dose-ranging studies were not performed, and little pharmacokinetic or pharmacodynamic information has been obtained. More importantly, because of the small numbers and short duration of treatment, safety concerns have not been addressed. Although L-arginine is a component of the diet (about 3-5 $\mathrm{g}$ /day in the western diet), little is known regarding the long-term consequences of supplementing dietary arginine. A number of studies have indicated benefit of L-arginine supplementation in patients with coronary artery disease and congestive heart failure, with improvements in endothelial vasodilator function, improvements in exercise tolerance, and relief of symptoms [46-50]. Furthermore, in the largest study of short-term arginine therapy, there was a strong tendency toward a reduction in cardiovascular morbidity [77]. In this 
randomized clinical trial, 792 patients with acute myocardial infarction (with ST segment elevation) were randomized to oral Larginine (3.0 t.i.d p.o. for 30 days) or placebo in addition to standard of care. The end point was the composite of 30 day cardiovascular death, reinfarction, resuscitation, shock/pulmonary edema or recurrent myocardial ischemia. These major adverse cardiovascular events occurred in $24 \%$ patients treated with $\mathrm{L}$-arginine and $27 \%$ with placebo (OR $0.63,95 \% \mathrm{Cl}$ 0.39-1.02, $\mathrm{p}=0.06$ ). No serious adverse effects were observed during L-arginine supplementation. Thus, in the short-term after a myocardial infarction, L-arginine was well tolerated. Furthermore, there was a tendency for a short- term benefit.

However, in a subsequent study, patients $(\mathrm{n}=150)$ patients with acute myocardial infarction were randomized to placebo or L-arginine supplementation for a longer term of therapy (6 months) following acute myocardial infarction. This trial was terminated early by the data and safety monitoring board when 8 deaths occurred in the arginine treated group [78].

The difference between these studies may be related to the duration of therapy. Although abundant evidence indicates that short-term administration of L-arginine is beneficial for endothelial vasodilator function and symptoms in patients with cardiovascular disease, one long-term study suggests that chronic administration of Larginine can induce a form of tolerance [79]. In 220 patients with peripheral arterial disease (PAD) we studied the potential benefit of L-arginine supplementation on endothelial vasodilator function and functional capacity. In a pilot study, patients with PAD and intermittent claudication $(n=80)$ were randomly assigned to oral doses of $0,3,6$ or $9 \mathrm{~g}$ of L-arginine daily in three divided doses for 12 weeks [85]. Treadmill testing was performed prior to administration of the study drug and again after 12 weeks of treatment. The study drug was well tolerated, with no significant adverse effects of Larginine administration. There was no significant difference observed in absolute claudication distance between the groups. However, a trend was observed for a greater increase in walking distance in the group treated with $3 \mathrm{~g}$ L-arginine daily, and there was a trend for an improvement in walking speed in patients treated with L-arginine. This pilot study provided data for safety, for power calculation and for dosing for the subsequent definitive trial.

In the definitive study, oral L-arginine ( $3 \mathrm{~g} / \mathrm{d}$ ) versus placebo for 6 months was assessed in subjects $(n=133)$ with intermittent claudication due to PAD. The primary end point was the change at 6 months in the absolute claudication distance as assessed by the Skinner-Gardner treadmill protocol. L-arginine supplementation significantly increased plasma L-arginine levels. However, measures of nitric oxide availability (including flow- mediated vasodilation, vascular compliance, plasma and urinary nitrogen oxides, and plasma citrulline formation) were reduced or not improved compared with placebo. Although absolute claudication distance improved in both L-arginine- and placebo- treated patients, the improvement in the Larginine-treated group was significantly less than that in the placebo group ( $28 \%$ versus $12 \%$; $\mathrm{p}<0.05$ ). Thus, in patients with PAD, long-term administration of L-arginine does not increase nitric oxide synthesis or improve vascular reactivity. Furthermore, the expected placebo effect observed in studies of functional capacity was attenuated in the L-arginine-treated group. As opposed to its short-term administration, long-term administration of L-arginine does not appear to be useful in patients with intermittent claudication and PAD.

This latter study raises questions about the long-term efficacy and safety of L-arginine supplementation. The study suggests that an 'arginine tolerance' or tachyphylaxis to the effects of chronic administration of L-arginine could even induce dysfunction of the NO synthase pathway. It is possible that other methods to enhance plasma L-arginine levels would be more effective. L-arginine undergoes extensive first-pass metabolism by arginase in the small intestine and liver. Administration of L-citrulline (the precursor of Larginine) escapes this degradation pathway, and increases plasma L-arginine levels to a greater extent than does Larginine supplementation. In this study, L-citrulline $3 \mathrm{~g}$ bid increased urinary nitrate and cGMP by $30 \%$ (reflecting increased NO synthesis and bioactivity). Indeed, Nobel laureate Louis Ignarro 
has given his imprimatur to a product containing L-citrulline (NiteworksO) that is said to increase NO production and enhance physical and sexual functioning. However, there are no long-term randomized clinical trials assessing the safety and efficacy of this dietary supplement for its intended use.

It is possible that intermittent administration of L-arginine may avoid the problem of ${ }^{\mathrm{t}}$ arginine tolerance' and maintain efficacy as an enhancer of penile NO synthesis. In which case, studies need to be done to validate this use, particularly during co- administration of pharmaceutical agents for erectile dysfunction. There is a known interaction of exogenous nitrates with PDE-5 inhibitors, such that the risk of hypotension is increased. Whether this adverse interaction might occur with L-arginine has not been definitively studied.

\section{Herbal Viagra and NO}

There are a number of other dietary supplements that purport to improve sexual function. Some of these may be of modest benefit, but the evidence is weak. Some of these agents may be hazardous, particularly for the many ED patients that also have known or occult coronary artery disease. The Food and Drug Administration has banned several of these products, some of which have contained PDE-5 inhibitors [80]. It is important to know that the regulation of supplements is not as rigorous as for pharmaceuticals. Manufacturers are obliged to follow good manufacturing practice (GMP) regulations promulgated by the US Food and Drug

Administration (FDA). These regulations require that the product meets purity specifications. However, manufacturers don't need FDA approval before going to market with their product. Once the product is on the market, the FDA is responsible for monitoring its safety, and if necessary can take remedial action (eg. issue a warning or require that the product be removed from the market).

The claims made by the distributors of the dietary supplement are regulated by the Dietary Supplement Health Education Act (DSHEA) of 1994, which permits the distributor to make structure or function claims, but prohibits claims regarding treatment of a disease. For example, a manufacturer of a calcium supplement can maintain that the product promotes bone health, but cannot claim that it is useful for the treatment of osteoporosis. They must also include a disclaimer that the FDA hasn't evaluated the claim. The claims that health food companies make about their products are usually based on research performed by other parties, frequently scientists at universities not affiliated with or supported by the health food companies. Because they don't perform their own research, these companies can sell their products at a lower cost (which is good for the consumer). But because they do not support research, they generally do not develop substantially new or more effective therapies (which is not good for the consumer), and they generally do not subject their products to rigorous testing, which is one of the reasons that the medical community is skeptical of dietary supplements. Finally, as one can imagine, because of the number of products on the market, and the limitations of the FDA budget, it is difficult to provide thorough oversight regarding the safety of these products once on the market.

Dietary supplements for sexual function include Korean red ginseng (Panax ginseng), yohimbe, Epimedium (horny goat weed), DHEA (dehydroepiandrosterone, a precursor of testosterone), anti-oxidants (Vitamin E, folate and zinc), ginkgo and L-arginine. Ginseng is an herb often brewed as a tea, and has been employed as a traditional Chinese remedy for diverse disorders. Small studies of ginseng suggest that the herb is safe and has modest benefit for individuals with erectile dysfunction [81]. Epimedium is another traditional Chinese medicine for erectile dysfunction that contains an active principle (icariin) with PDE-5 inhibitory activity [82]. However, no randomized clinical trials have assessed safety or efficacy. Yohimbe is derived from the bark of a West African evergreen containing a variety of pharmacologically active chemicals. The major active moiety is yohimbine, an alpha 2 adrenergic antagonist. There is 
pre-clinical evidence, and some clinical experience indicating that yohimbine can enhance sexual function [83-85]. However, yohimbine can increase heart rate and blood pressure [86], which is of particular concern for individuals with cardiovascular disease (common in men with erectile dysfunction). The rationale for the use of DHEA is that this chemical is a precursor to testosterone. However, there is little evidence for the efficacy of DHEA [87]. For that matter, the literature supporting the use of pharmaceutical testosterone for erectile dysfunction is mixed [1].

The antioxidant vitamins may reduce oxidative stress, and thereby preserve NO from oxidative inactivation so as to improve endothelium dependent vasodilation [88]. Similarly, gingko may preserve NO from oxidative degradation [89] to improve vascular reactivity. L-arginine is the precursor for NO, providing a rationale for its administration in erectile dysfunction. The level of evidence that a dietary supplement can enhance NO production is arguably the strongest for L-arginine, yet questions remain regarding efficacy and safety. For more information regarding the other dietary supplements, good sources of information include the National Center for Complementary and Alternative Medicine (NCCAM) and the Office of Dietary Supplements $[90,91]$.

\section{Conclusions}

There is compelling evidence that the NOS pathway is critical for erectile function, and that a derangement of neuronal and endothelial NO signaling is a major contributor to erectile dysfunction in a majority of patients. Furthermore, bolstering the NOS pathway with PDE-5 inhibitors has been a very effective pharmacological approach to treating impotence. Therefore herbal supplements that enhance NO synthesis or reduce its degradation could be useful for enhancing erectile function. The nutritional product with the strongest rationale for this use is L-arginine, which in pre-clinical studies and in small clinical studies of short duration, has been shown to enhance NO synthesis.

However, with respect to the notion that L-arginine or other dietary supplements may safely and effectively improve erectile function, the evidence is soft. A few randomized clinical trials of short duration in small groups of patients suggest modest benefit. However, there is no evidence of long-term efficacy and safety, as definitive trials of chronic L-arginine administration have not been done in patients with erectile dysfunction. Furthermore, there is scant information regarding potential interactions with other medications. Finally, because erectile dysfunction is often associated with cardiovascular disease, self-treatment with herbal remedies, in the absence of physician supervision, is risky. Individuals with erectile dysfunction should be evaluated by their physician for cardiovascular disease, and offered effective pharmacotherapy for sexual function.

\section{Additional Information}

\section{Disclosures}

Conflicts of interest: In compliance with the ICMJE uniform disclosure form, all authors declare the following: Payment/services info: This work was supported by grants from the National Institutes of Health (R01 HL- 75774, R21 HL085743, K12 HL087746, P50HL083800, RC2HL103400, 1U01HL100397), the California Tobacco Related Disease Research Program of the University of California (18XT-0098), and The Wallace H. Coulter Translational Research Grant Program. Financial relationships: John Cooke declare(s) an alternate financial activity from NiCox. Consultant. Intellectual property info: Dr. Cooke is the inventor of patents owned by Stanford University for diagnostic and therapeutic applications of the NOS pathway from which he receives royalties. Other relationships: All authors have declared that there are no other relationships or activities that could appear to have influenced the submitted work. 


\section{References}

1. Tsertsvadze A, Fink HA, Yazdi F, MacDonald R, Bella AJ, Ansari MT, Garritty C, Soares-Weiser K, Daniel R, Sampson M, Fox S, Moher D, Wilt TJ: Phosphodiesterase-5 inhibitors and hormonal treatments for erectile dysfunction: a systematic review and meta-analysis. Ann Intern Med. 2009, 151:650-661. 10.7326/0003-4819-151-9-200911030-00150

2. Feil R, Lohmann S, de Jonge H, Walter U, Hofmann F: Cyclic GMP-dependent protein kinases and the cardiovascular system: insights from genetically modified mice. Circ Res. 2003, 93:907-916. 10.1161/01.RES.0000100390.68771.CC

3. Bian K, Murad F: Nitric oxide (NO)--biogeneration, regulation, and relevance to human diseases. Front Biosci. 2003, 8:264-278.

4. Rajfer J, Aronson W, Bush P, Dorey F, Ignarro U: Nitric oxide as a mediator of relaxation of the corpus cavernosum in response to nonadrenergic, noncholinergic neurotransmission. $\mathrm{N}$ Engl J Med. 1992, 9:90-94. 10.1056/NEJM199201093260203

5. Podlasek C, Zelner D, Bervig T, Gonzalez C, McKenna K, McVary K: Characterization and localization of nitric oxide synthase isoforms in the BB/WOR diabetic rat. J Urol. 2001, 166:246-255.

6. Stanarius A, Uckert S, Machtens S, Stief C, Wolf G, Jonas U: Immunocytochemical distribution of nitric oxide synthase in the human corpus cavernosum: an electron microscopical study using the tyramide signal amplification technique. Urol Res. 2001, 29: 168-172.

7. Azadzoi K, Master T, Siroky M: Effect of chronic ischemia on constitutive and inducible nitric oxide synthase expression in erectile tissue. J Androl. 2004, 25:382-388.

8. Musicki B, Ross A, Champion H, Burnett A, Bivalacqua T: Post translational modification of constitutive nitric oxide synthase in the penis. J Androl. 2009, 30:352-362. 10.2164/jandrol.108.006999

9. Cooke J, Rossitch E, Andon N, Loscalzo J, Dzau V: Flow activates an endothelial potassium channel to release an endogenous nitrovasodilator. J Clin Invest. 1991, 88:1663-1671.

10.1172/JCI115481

10. WesselIs H, Teal T, Engel K, Sullivan C, Gallis B, Tran K, Chitaley K: Fluid shear stressinduced nitric oxide production in human cavernosal endothelial cells: inhibition by hyperglycaemia. BJU Int. 2006, 97:1047-1052. 10.1111/j.1464-410X.2006.06059.x

11. Hurt K, Musicki B, Palese M, Crone J, Becker R, Moriaruty J, Snyder S, Burnett A: Aktdependent phosphorylation of endothelial nitric oxide synthase mediated penile erection. Proc Natl Acad Sci USA. 2002, 99:4061-4066. 10.1073/pnas.052712499

12. Muhall JP, MuIler A, Donohue J, Mullerad M, Kobylarz K, Paduch D, Tal R, Li P, Cohen-Gould L, Scardino P: The functional and structural consequences of cavernous nerve injury are ameliorated by sildenafil citrate. J Sex Med. 2008, 5:1126-1136. 10.1111/j.17436109.2008.00794.x

13. Creager M, Cooke J, Mendelsohn M, Gallagher S, Coleman S, Loscalzo J, Dzau V: Impaired vasodilation of forearm resistance vessels in hypercholesterolemic humans. J Clin Invest. 1990, 86:1813-1818. 10.1172/JCI114688

14. Cooke J: Asymmetrical dimethylarginine: the Uber marker? . Circulation. 2004, 109:18131818. 10.1161/01.CIR.0000126823.07732.D5

15. Stamler J, Mendelsohn M, Amarante P, Smick D, Andon N, Davies P, Cooke J, Loscalzo J: Nacetylcysteine potentates platelet inhibition by endothelium-derived relaxing factor. Circ Res. 1989, 65:789-795.

16. Cooke J, Stamler J, Andon N, Davies P, Mendelsohn M, Loscalzo J: Flow-mediated endothelium-dependent effects on platelet and vascular reactivity. Endothelium-Derived Relaxing Factors. Karger (ed): Karger Press, Basel, Switzerland; 1990. 1:244-253.

17. Tsao P, McEvoy L, Drexler H, Butcher E, Cooke J: Enhanced endothelial adhesiveness in hypercholesterolemia is attenuated by L-arginine. Circulation. 1994, 89:2176-2182.

18. Tsao P, Lewis N, Alpert S, Cooke J: Exposure to shear stress alters endothelial adhesiveness: Role of nitric oxide. Circulation. 1995, 92:3513-3519.

19. Tsao P, Buitrago R, Chan J, Cooke J: Fluid flow inhibits endothelial adhesiveness: Nitric oxide and transcriptional regulation of VCAM-1. Circulation. 1996, 94:1682-1689.

20. Tsao P, Wang B, Buitrago R, Shyy J, Cooke J: Nitric oxide regulates monocyte chemotactic protein-1. Circulation. 1997, 96:934-940.

21. Cooke J, Singer A, Tsao P, Zera P, Rowan R, Billingham M: Antiatherogenic effects of L- 
arginine in the hypercholesterolemic rabbit. J Clin Invest. 1992, 90:1168-1172.

22. von der Leyen H, Gibbons G, Morishita R, Lewis N, Zhang L, Nakajima M, Kaneda Y, Cooke J, Dzau V: Gene therapy inhibiting neointimal vascular lesion: In vivo transfer of endothelial cell nitric oxide synthase gene. Proc Natl Acad Sci USA. 1995, 92:1137-1141.

23. Candipan R, Wang B, Buitrago R, Tsao P, Cooke J: Regression or progression: Dependency upon vascular nitric oxide. Arterioscler Thromb Vasc Biol. 1996, 16:44-50.

24. Schachinger V, Britten M, Zeiher A: Prognostic impact of coronary vasodilator dysfunction on adverse long-term outcome of coronary heart disease. Circulation. 2000, 101:1899-1906. 10.1161/01.CIR.101.16.1899

25. Suwaidi J, Hamasaki S, Higano S, Nishimura R, Holmes D Jr, Lerman A: Long-term follow-up of patients with mild coronary artery disease and endothelial dysfunction. Circulation. 2000, 101:948-954.

26. Gokce N, Keaney J Jr, Hunter L, Watkins M, Nedeljkovic Z, Menzoian J, Vita J: Predictive value of noninvasively determined endothelial dysfunction for longterm cardiovascular events in patients with peripheral vascular disease. J Am Coll Cardiol. 2003, 41:1769-1775.

27. Bivalacqua T, Champion H, Usta M, Cellek S, Chitaley K, Webb R, Lewis R, Mills T, Hellstrom W, Kadowitz P: RhoA/ Rho-kinase suppresses endothelial nitric oxide synthase in the penis: a mechanism for diabetes-associated erectile dysfunction. Proc Natl Acad Sci USA. 2004, 101:9121-9126. 10.1073/pnas.0400520101

28. Bivalacqua T, Usta M, Kendirci M, Pradhan L, Alvarez X, Champion H, Kadowitz P, Hellstrom W: Superoxide anion production in the rat penis impairs erectile function in diabetes: influence of in vivo extracellular superoxide dismutase gene therapy. J Sex Med. 2005, 2:187197. 10.1111/j.1743-6109.2005.20228_1.X

29. Musicki B, Kramer M, Becker R, Burnett A: Inactivation of phosphorylated endothelial nitric oxide synthase (Ser-1177) by OGIcNAc in diabetes-associated erectile dysfunction. Proc Natl Acad Sci USA. 2005, 102:11870-11875.

30. Brownlee M: The pathobiology of diabetic complications: a unifying mechanism . Diabetes. 2005, 54:1615-1625.

31. Hink U, Li H, Mollnau H, Oelze M, Matheis E, Hartmann M, Skatchkov M, Thaiss F, Stahl R, Warnholtz A, Meinertz T, Griendling K, Harrison D, Forstermann U, Munzel T: Mechanisms underlying endothelial dysfunction in diabetes mellitus. Circ Res. 2001, 88:14-22.

32. Wells L, Vosseller K, Hart G: Glycosylation of nucleocytoplasmic proteins: signal transduction and 0-GIcNAc. Science. 2001, 291:2376-2378.

33. Musicki B, Kramer M, Becker R, Burnett A: Age-related changes in phosphorylation of endothelial nitric oxide synthase in the rat penis. J Sex Med. 2005, 2:347-357.

34. Musicki B, Champion H, Becker R, Liu T, Kramer M, Burnett A: Erection capability is potentiated by chronic sildenafil treatment: role of blood flow-induced endothelial nitric oxide synthase phosphoryrylation. Mol Pharmacol. 2005, 68:226-232.

10.2164/jandrol.108.006999

35. Musicki B, Liu T, Strong T, Jin L, Laughlin M, Turk J, Burnett A: Low-fat diet and exercise preserve eNOS regulation and endothelial function in the penis of early atherosclerotic pigs: a molecular analysis. J Sex Med. 2008, 5:552-561.

36. Cooke J, Andon N, Girerd X, Hirsch A, Creager M: Arginine restores cholinergic relaxation of hypercholesterolemic rabbit thoracic aorta. Circulation. 1991, 83:1057-1062.

37. Creager M, Gallagher S, Girerd X, Coleman S, Dzau V, Cooke J: Larginine improves endothelium-dependent vasodilation in hypercholesterolemic humans. J Clin Invest. 1992, 90:1248-1253. 10.1172/JCI115987

38. Mugge A, Harrison D: L-arginine does not restore endothelial dysfunction in atherosclerotic rabbit aorta in vitro. Blood Vessels. 1991, 28:354-357. 10.1159/000158881

39. Pollock J, Forstermann U, Mitchell J, Warner T, Schmidt H, Nakane M, Murad F: Purification and characterization of particulate endothelium-derived relaxing factor synthase from cultured and native bovine aortic endothelial cells. Proc NatlAcadSci USA. 1991, 88:1048010484.

40. Drexler H, Zeiher A, Meinzer K, Just H: Correction of endothelial dysfunction in coronary micro-circulation of hypercholesterolaemic patients by L-arginine. Lancet. 1991, 338:15461550.

41. Kuo L, Davis M, Cannon M, Chilian W: Pathophysiological consequences of atherosclerosis extend into the coronary microcirculation. Restoration of endothelium- dependent responses 
by L-arginine. Circ Res. 1992, 70:465-476.

42. Randall M, Ujiie H, Griffith T: L-arginine reverses the impairment of nitric oxide-dependent collateral perfusion in dietary-induced hypercholesterolaemia in the rabbit. Clini Sci. 1994, 87:53-59.

43. Davies M, Dalen H, Kim J, Barber L, Svendsen E, Hagen P: Control of accelerated vein graft atheroma with the nitric oxide precursor: L-arginine. J Surg Res. 1995, 59:35-42.

10.1006/jsre.1995.1129

44. Clarkson P, Adams M, Powe A, Donald A, McCredie R, Robinson J, et al.: Oral L-arginine improves endothelium-dependent dilation in hypercholesterolemic young adults. J Clin Invest. 1996, 97:1989-1994. 10.1172/JCI118632

45. Egashira K, Hirooka Y, Kuga T, Mohri M, Takeshita A: Effects of L-arginine supplementation on endothelium-dependent coronary vasodilation in patients with angina pectoris and normal coronary arteriograms. Circulation. 1996, 94:130-134.

46. Lerman A, Burnett J Jr, Higano S, McKinley L, Holmes R Jr: Long-term Larginine supplementation improves small-vessel coronary endothelial function in humans. Circulation. 1998, 97:2123-2128. 10.1161/01.CIR.97.21.2123

47. Ceremuzynski L, Chamiec T, Herbaczynska-Cedro K: Effect of supplemental oral L-arginine on exercise capacity in patients with stable angina pectoris. Am J Cardiol. 1997, 80:331-333.

48. Ceremuzynski L, Tomasz C, Herbaczynska-Cedro K: L-arginine improves exercise capacity in patients with stable angina. J Am Coll Cardiol . 1997, 29:157.

49. Boger R, Bode-Boger S, Thiele W, Alexander K, Frolich J: Biochemical evidence for impaired nitric oxide synthesis in patients with peripheral arterial occlusive disease. Circulation. 1998, 95:2068-2074.

50. Rector T, Bank A, Mullen K, Tschmumperlin L, Sih R, Pillai K, et al.: Randomized, doubleblind, placebo-controlled study of supplemental oral L-arginine in patients with heart failure. Circulation. 1996, 93:2135-2141.

51. Bode-Boger S, Scalera F, Ignarro U.: The L-arginine paradox: importance of the Larginine/asymmetrical dimethylarginine ratio. Pharmacol Ther. 2007, 114:295-306. 10.1016/j.pharmthera.2007.03.002

52. Valiance P, Leone A, Calver A, et al.: Accumulation of an endogenous inhibitor of nitric oxide synthesis in chronic renal failure. Lancet. 1992, 339:572-575.

53. Zakrzewicz D, Eickelberg 0: From arginine methylation to ADMA: a novel mechanism with therapeutic potential in chronic lung diseases. BMC Pulm Med. 2009, 29:5. 10.1186/14712466-9-5

54. McDermott J: Studies on the catabolism of NG-methylarginine, NG,N'Gdimethylarginine and NG,NG-dimethylarginine. Biochem J. 1976, 154:179-184.

55. Leiper J, Santa Maria J, Chubb A et al.: Identification of two human dimethylarginine dimethylaminohydrolases with distinct tissue distributions and homology with microbial arginine deiminases. Biochem J. 1999, 343:209-214.

56. Murray-Rust J, Leiper J, McAlister M, Phelan J, Tilley S, Santa Maria J, Valiance P, McDonald $\mathrm{N}$ : Structural insights into the hydrolysis of cellular nitric oxide synthase inhibitors by dimethylarginine dimethylaminohydrolase. Nat Struct Biol. 2001, 8:679-683.

57. Ito A, Tsao P, Adimoolam S, Kimoto M, Ogawa T, Cooke J: Novel Mechanism for Endothelial Dysfunction : Dysregulation of Dimethylarginine Dimethylaminohydrolase. Citation. 1999, 99:3092-3095.

58. Stuhlinger M, Tsao P, Her J, Kimoto M, Balint R, Cooke J: Homocysteine impairs the nitric oxide synthase pathway: role of asymmetric dimethylarginine. Circulation. 2001, 104:25692575 .

59. Lin K, Ito A, Asagami T, Tsao P, Adimoolam S, Kimoto M, Tsuji H, Reaven G, Cooke J: Impaired nitric oxide synthase pathway in diabetes mellitus: Role of asymmetric dimethylarginine and dimethylarginine dimethylaminohydrolase. Circulation. 2002, 106:987992. 10.1161/01.CIR.0000027109.14149.67

60. Miyazaki H, Matsuoka H, Cooke J, et al.: Endogenous nitric oxide synthase inhibitor: a novel marker of atherosclerosis. Circulation. 1999, 99:1141-1146. 10.1161/01.CIR.99.9.1141

61. Zoccali C, Bode-Boger S, Mallamaci F et al.: Plasma concentration of asymmetrical dimethylarginine and mortality in patients with end-stage renal disease: a prospective study. Lancet. 2001, 358:2113-2117.

62. Mittermayer F, Krzyzanowska K, Exner M, Mlekusch W, Amighi J, Sabeti S, Minar E, Muller M, 
Wolzt M, Schillinger M: Asymmetric dimethylarginine predicts major adverse cardiovascular events in patients with advanced peripheral artery disease. Arteriosclerosis, thrombosis, and vascular biology. 2006, 26:2536-2540. 10.1177/1358863X10364552

63. Wilson A, Shin D, Weatherby C, Harada R, Ng M, Nair N, Kielstein J and Cooke J: Asymmetric dimethylarginine predicts adverse cardiovascular events and mortality in peripheral arterial disease. Vascular Medicine. 2010,

64. Aktoz T, Aktoz M, lath E, Kaplan M, Turan F, Barutcu A, Atakan I, Demir M, Altun A: Assessment of the relationship between asymmetric dimethylarginine and severity of erectile dysfunction and coronary artery disease. Int Urol Nephrol. 2010,

65. Maas R, Wenske S, Zabel M, Ventura R, Schwedhelm E, Steenpass A, Klemm H, Noldus J, Berger R: Elevation of asymmetrical dimethylarginine (ADMA) and coronary artery disease in men with erectile dysfunction. Eur Urol. 2005, 48:1004-1011.

66. Wierzbicki A, Solomon H, Lumb P, Lyttle K, Lambert-Hammill M, Jackson G: Asymmetric dimethyl arginine levels correlate with cardiovascular risk factors in patients with erectile dysfunction. Atherosclerosis. 2006, 185:421-425. 10.1016/j.atherosclerosis.2005.06.025

67. Park K, Lee D, Kim S, Paick J: Dimethylarginine dimethylaminohydrolase in rat penile tissue: reduced enzyme activity is responsible for erectile dysfunction in a rat model of atherosclerosis. Int J Impot Res. 2009, 21:228-234. 10.1038/ijir.2009.20

68. Moody J, Vernet D, Laidlaw S, Rajfer J, Gonzalez-Cadavid N: Effects of longterm oral administration of L-arginine on the rat erectile response. J Urol. 1997, 158:942-947.

69. Gur S, Kadowitz P, Trost L, Hellstrom W: Optimizing nitric oxide production by time dependent L-arginine administration in isolated human corpus cavernosum. J Urol. 2007, 178:1543-1548. 10.1016/j.juro.2007.05.121

70. Zorgniotti A, Lizza E: Effect of large doses of the nitric oxide precursor, Larginine, on erectile dysfunction. Int J Impot Res. 1994, 6:33-35.

71. Chen J, Wollman Y, Chernichovsky T, laina A, Sofer M, Matzkin H: Effect of oral administration of high-dose nitric oxide donor L-arginine in men with organic erectile dysfunction: results of a double-blind, randomized, placebo-controlled study. BJU Int. 1999, 83:269-273.

72. Klotz T, Mathers M, Braun M, Bloch W, Engelmann U: Effectiveness of oral Larginine in firstline treatment of erectile dysfunction in a controlled crossover study. Urol Int. 1999, 63:220223.

73. Oka R, Szuba A, Giacomini J, Cooke J: A pilot study of L-arginine supplementation on functional capacity in peripheral arterial disease. Vascular Medicine. 2005, 10:265-274. 10.1191/1358863x05vm637oa

74. Lebret T, Herve J, Gorny P, Worcel M, Botto H: Efficacy and safety of a novel combination of L-arginine glutamate and yohimbine hydrochloride: a new oral therapy for erectile dysfunction. Eur Urol. 2002, 41:608-613.

75. Gentile V, Antonini G, Antonella Bertozzi M, DineIli N, Rizzo C, Ashraf Virmani M, Koverech A: Effect of propionyl-L-carnitine, L-arginine and nicotinic acid on the efficacy of vardenafil in the treatment of erectile dysfunction in diabetes. Curr Med Res Opin. 2009, 25:2223-2228.

76. Stanislavov R, Nikolova V, Rohdewald P: Improvement of erectile function with Prelox: a randomized, double-blind, placebo-controlled, crossover trial. Int J Impot Res. 2008, 20:173180. 10.1038/sj.ijir.3901597

77. Bednarz B, Jaxa-Chamiec T, Maciejewski P, Szpajer M, Janik K, Gniot J, KawkaUrbanek T, Drozdowska D, Gessek J, Laskowski H: Efficacy and safety of oral l-arginine in acute myocardial infarction - Results of the multicenter, randomized, double- blind, placebocontrolled ARAMI pilot trial. Kardiol Pol. 2005, 62:421-427.

78. Schulman S, Becker L, Kass D, Champion H, Terrin M, Forman S, Ernst K, Kelemen M, Townsend S, Capriotti A, Hare J, Gerstenblith G: L-arginine therapy in acute myocardial infarction: the Vascular Interaction With Age in Myocardial Infarction (VINTAGE MI) randomized clinical trial. JAMA. 2006, 295:58-64. 10.1001/jama.295.1.58

79. Wilson A, Harada R, Nair N, Balasubramanian N, Cooke J: L-arginine supplementation in peripheral arterial disease: no benefit and possible harm. Circulation. 2007, 116:188-195. 10.1161/CIRCULATIONAHA.106.683656

80. Schwedhelm E, Maas R, Freese R, Jung D, Lukacs Z, Jambrecina A, Spickler W, Schulze F, Boger R: Pharmacokinetic and pharmacodynamic properties of oral L citrulline and Larginine: impact on nitric oxide metabolism. Br J Clin Pharmacol. 2007, 65:51-9. Accessed: 


\section{Cureus}

January 2008:

81. U.S. Food and Drug Administration. (2008). Accessed: December 3, 2008: http://www.fda.gov/Safety/Recalls/EnforcementReports/2008/ucm120534.htm.

82. Jang D, Lee M, Shin B, Lee Y, Ernst E: Red ginseng for treating erectile dysfunction: a systematic review. Br J Clin Pharmacol. 2008, 66:444-450. Accessed: June 9, 2008:

83. Dell'Agli M, Galli G, Dal Cero E, Belluti F, Matera R, Zironi E, Pagliuca G, Bosisio E: Potent inhibition of human phosphodiesterase-5 by icariin derivatives. J Nat Prod. 2008, 71:15131517. Accessed: September 9, 2008:

84. Fernandez-Guasti A, Rodriguez-Manzo G: Pharmacological and physiological aspects of sexual exhaustion in male rats. Scand J Psycho. 2003, 44:257-263.

85. Yonezawa A, Yoshizumii M, Ebiko M, Amano T, Kimura Y, Sakurada S: Long-lasting effects of yohimbine on the ejaculatory function in male dogs. Biomed Res . 2005, 26(5):201-206. 10.2220/biomedres.26.201

86. Guidance for Industry: Botanical drug products. 2004, 45.

87. Morales A, Black A, Emerson L, Barkin J, Kuzmarov I, Day A: Androgens and sexual function: a placebo-controlled, randomized, double-blind study of testosterone vs. dehydroepiandrosterone in men with sexual dysfunction and androgen deficiency. Aging Male. 2009, 12:104-112. 10.3109/13685530903294388.

88. Levine G, Frei B, Koulouris S, Gerhard M, Keaney J Jr, Vita J: Ascorbic acid reverses endothelial vasomotor dysfunction in patients with coronary artery disease. Citation. 1996, 93:1107-1113.

89. Li X, Zheng W, Lou S, Lu X, Ye S: Effect of Ginkgo leaf extract on vascular endothelial function in patients with early stage diabetic nephropathy. Chin J Integr Med. 2009, 15:26-29.

$10.1155 / 2013 / 343594$

90. http://nccam.nih.gov/.

91. http://dietary-supplements.info.nih.gov/. 